\title{
La reconfiguración del discurso histórico en la Nueva Novela Histórica Hispanoamericana: Los pasos de López, de Jorge Ibargüengoitia.
}

\section{Reconfiguration of Historical Discourse in the Latin American New Historical Novel: Los Pasos de López, by Jorge Ibargüengoitia.}

\author{
Ismael Antonio Borunda Magallanes \\ Instituto de Investigación en Humanidades y Ciencias Sociales / Universidad Autónoma del Estado \\ de Morelos (MÉXICO) \\ CE: iab site@hotmail.com ID ORCID: 0000-0002-7883-422X
}

DOI: $10.32870 /$ sincronia.axxiii.n76.28b19 $\mathrm{BY} \cdot \mathrm{NC}$ Esta obra está bajo una Licencia Creative Commons Atribución-NoComercial 4.0 Internacional

Recibido: 30/03/2019

Revisado: 17/04/2019

Aprobado: 30/05/2019

\section{RESUMEN}

En este artículo se presenta un panorama general descriptivo de la Nueva Novela Histórica Hispanoamericana, género literario narrativo aparecido en América Latina a partir de la segunda mitad del siglo XX y nombrado originalmente por Seymour Menton. Esta descripción servirá como marco teórico para el análisis de la novela del mexicano Jorge Ibargüengoitia, Los pasos de López, en la que se desarrollan los principales preceptos del género, así como una particular ideología frente el discurso histórico oficial en México.

Palabras clave: Nueva Novela Histórica Hispanoamericana. Literatura latinoamericana. Teoría literaria. Narrativa. Historia. 


\begin{abstract}
:
This artcile presents a general descriptive overview of the Latin American New Historical Novel, literary genre orignated in this region during the second half of the XX century, first named by Seymour Menton. This overview will function as a theoretical framework for the analysis of Los pasos de López, a novel written by the mexican author Jorge Ibargüengoitia, in which the most important precepts of this genre are developed, as well as a particular idelogical stance regarding the official historical discourse in Mexico.
\end{abstract}

Keywords: Latin American New Historical Novel. Latin American Literature. Literary Theory. Narrative. History.

\title{
Introducción
}

La ficción como configuración de relatos da pie a representar cualquier suerte de experiencia humana, ya sea mediante la confección de historias novedosas y fantásticas o la reconstrucción de hechos verídicos, una biografía o un evento particular. Si la ficción consiste en dotar a la realidad, por sí misma convulsa, de lógica y coherencia narrativa en el tiempo y el espacio, ¿en qué se diferencia de la historia, la ciencia que dota de lógica y coherencia narrativa a los hechos del pasado? No en mucho, sus lindes se desvanecen en cuanto se intenta esclarecerlos, pero es posible distinguirlos lo suficiente como para dar a cada discurso su lugar en el desarrollo de la cultura y el conocimiento humanos.

La literatura en Hispanoamérica ha aprovechado esta frontera nebulosa entre la historia y la ficción con el fin abordar uno de los problemas más trascendentales para la conformación de la identidad hispanoamericana: la influencia de su realidad histórica en su realidad presente. Este fenómeno cultural no responde únicamente a la necesidad de relacionar el devenir de los hechos históricos con la manera en que la actual sociedad estructura sus múltiples facetas, sino también con otra necesidad más primigenia, la de comprender la existencia de la propia cultura, identificarla en sus elementos más básicos de manera intrínseca, y en comparación con el resto de las culturas 
en el mundo, punto especialmente relevante en la realidad cosmopolita e interconectada de la contemporaneidad. Es así que se originan los textos de la Nueva Novela Histórica Hispanoamericana $(\mathrm{NNHH})$, género narrativo que toma los elementos temáticos de la historia como disciplina científica y reconfigura su discurso para transformarla en realidad ficticia; no falsa, no alterada, sino reconstruida, entendida desde perspectivas distintas a las de la historia institucional, esa que sirve de estandarte para las esferas de poder que obstaculizan el desarrollo integral y digno de la sociedad y contra la que los autores que adoptan esta manera de narrar se revelan.

En este artículo se presenta un caso de análisis de justamente estos factores en la novela del escritor mexicano, Jorge Ibargüengoitia, Los pasos de López, reconocida desde su publicación en 1982 como un incisivo atentado literario contra la hegemonía de una identidad histórica construida desde lo que institucionalmente se ha reconocido como verdadero y absoluto. El texto se propone entonces como postura ideológica ante la realidad histórica en México, y como entrega literaria enmarcada en la tendencia más amplia de la NNHH de finales del siglo XX. Para llegar a esa conclusión, se presenta primero una reflexión en torno al propio género, sus orígenes, sus motivaciones y su colocación en la cultura de Hispanoamérica, y posteriormente una breve contextualización para vislumbrar un pertinente horizonte de expectativas del texto que permita enmarcar su análisis.

\section{La Nueva Novela Histórica Hispanoamericana como fenómeno literario y cultural}

Trazar nítidamente los márgenes de la novela histórica como género o corriente literaria es más complicado que simplemente redactar una lista de requerimientos temáticos y formales. La historia como disciplina de las humanidades trata sobre el ser humano y los acontecimientos que lo involucran ocurridos en el pasado, por lo que la novela histórica parecería implicar sin más a las narraciones literarias que tomen estos acontecimientos pasados como tema de sus obras. Sin embargo, este criterio da muestras de ser demasiado amplio para justificar la denominación de un solo género y, más importante aún, la trascendencia del tratamiento que hacen los autores literarios de temas que son considerados históricos. 
Una de las explicaciones más importantes de las últimas décadas del siglo XX, especialmente trascendental para los estudios de literatura en Hispanoamérica, es la que hace Seymour Menton para diferenciar a la Nueva Novela Histórica de la tradicional. Primeramente, hace mención de que, "en el sentido más amplio, toda novela es histórica, puesto que, en menor o mayor grado, capta el ambiente social de sus personajes, hasta de los más introspectivos" (1993, p. 32). Obviamente ésta no es la definición por la que se guiará Menton para su estudio, pero sí arroja luz sobre la condición de su criterio, el cual describe de la siguiente manera: "Hay que reservar la categoría de novela histórica para aquellas novelas cuya acción se ubica total, o por lo menos predominantemente en el pasado, es decir, un pasado no experimentado directamente por el autor" (Menton, 1993, p. 32).

Luego de esta delimitación, el autor describe el camino y las variaciones del género a partir del siglo XIX en el marco del romanticismo, para luego sujetarse al realismo de finales de aquel siglo y comienzos del $\mathrm{XX}$, que vio mucho más prolíficas las narraciones que trataban situaciones contemporáneas, lo que las excluye de la clasificación histórica según el criterio planteado.

Hasta este momento sigue identificándose únicamente la novela histórica dentro de la producción literaria latinoamericana (no solamente hispanoamericana, porque Seymour Menton considera para su estudio también las obras de autores brasileños). Es en 1949 cuando aparece El reino de este mundo de Alejo Carpentier, autor trascendental en la concepción y auge de la Nueva Novela Histórica, en la que se esbozan ya muchas características discursivas específicas que vuelven a las narraciones ya no sólo recreaciones de un contexto histórico, sino interpretaciones y reconfiguraciones tanto de la historia misma como de la manera en que es contada, muy pertinente para lo que entonces estaba ocurriendo en la literatura hispanoamericana y que desembocaría en el conocido "Boom". En la novela de Carpentier se cuenta la historia de las luchas por la independencia de Haití desde mediados del siglo XVIII hasta principios del XIX, tomando a diversas personalidades históricas como protagonistas de los relatos narrados, todos ellos ligados por la figura mítico-histórica de Ti Noel, y en la que intervienen elementos de lo llamado por el propio Carpentier como real-maravilloso, por lo que ya este autor ofrece una obra que esboza las 
características que para Seymour Menton (1993, pp. 38-39) identifican una clara, nueva, tendencia en la representación literaria de la historia en Latinoamérica.

No obstante, es hasta 1979 que el mismo Alejo Carpentier publica El arpa y la sombra, la cual ya no deja resquicio en su construcción discursiva por el que se le pueda desligar del nuevo género. En la novela el protagonista es Cristóbal Colón, a quien se construye como un personaje con particulares vicios y afecciones que le confieren una condición mucho menos mítica o idealizadora a la del discurso histórico institucional. Por otra parte, el lenguaje barroco de la narración y la intervención de situaciones carnavalescas desarticulan la mera ficcionalización de la narración histórica.

A partir de estas obras y de la línea literaria que trazan hasta finales del siglo XX, Menton construye seis características fundamentales de las narraciones que constituyen la Nueva Novela Histórica como género, y que pueden ser resumidas de la siguiente manera: 1) subordinación de la recreación mimética de hechos históricos a la presentación de ideas filosóficas, 2) la distorsión consciente de estos hechos mediante recursos retóricos, 3) ficcionalización de personajes históricos como protagonistas, 4) la metaficción, referencia en el propio texto al proceso creativo, 5) la intertextualidad y 6) el empleo de los conceptos de Bajtín sobre dialogismo, lo carnavalesco, la parodia y la heteroglosia. Se aclara que una novela puede no presentar cada una de las características descritas para formar parte de esta categoría (Menton, 1993, pp. 42-45).

Seymour Menton deslinda algunas importantes obras de narrativa histórica contemporánea de su clasificación como NNH por, entre algunas otras razones, no enfatizar sus elementos formales, principalmente el neobarroquismo. Por otra parte, otorga la categoría de novela histórica a obras como El amor en los tiempos del cólera por ocurrir en un tiempo histórico "real" anterior a la vida de su autor, motivo por el que deslinda -y no por ningún otro, aparentemente- también a Cien años de soledad, pues la última generación que aparece en la narración es contemporánea a la vida del autor (1993, pp. 31-34).

Es posible advertir cierta arbitrariedad en estos criterios para incluir o excluir a unas y otras obras de lo que puede llamarse novela histórica (no necesariamente de la NNH, que sí queda mucho 
más claramente delimitada). Para Menton sólo hace falta que la novela ocurra en un tiempo anterior a la vida del autor para ser histórica, no que los personajes y la trama hayan sido tomados de hechos relevantes para la historia social y culturalmente.

Con respecto de esto se abre otra interrogante: ¿cuáles hechos son propiamente históricos? Según el criterio de Menton, basta con que hayan ocurrido en el pasado, pero ninguna de las novelas que él y la crítica literaria consideran para el estudio del género plasman en su agentes protagónicos hechos de vidas cotidianas, de familias del campo, por ejemplo, o de burócratas anónimos, ni escenas autobiográficas. ¿Cualquier novela basada en un hecho o contexto verídico es una novela histórica? La relevancia de los hechos pasados es, evidentemente, una tarea que no sólo es responsabilidad de la literatura, sino en primera instancia de la historia como disciplina. No obstante, es también evidente que la prominencia del género dentro de la crítica y la historia literaria en Hispanoamérica, así como en cualquier otra región en que este género se haya desarrollado de algún modo, no responde únicamente a que su trama ocurra en el pasado; de ser así, cualquier novela que narre el tiempo mismo de la vida de su escritor se convertirá inmediatamente en novela histórica en cuanto termine de ser escrita (o al menos a partir de la muerte de su autor, según la lógica de Menton).

No, las novelas históricas, como tendencia y como género, se preocupan por los hechos y los personajes que, tanto para el imaginario literario como para el conocimiento histórico, determinaron la configuración política y social de sus pueblos, que articulan los vértices de la realidad histórica de toda una nación o de una comunidad que tiene íconos y rasgos de identidad comunes entre sus miembros. Peter Elmore en La fábrica de la memoria lo explica de la siguiente manera:

No basta una brecha de varias décadas o siglos entre el presente de la escritura y el de los personajes para que una narración ficcional pertenezca al rubro de lo histórico. [...] Cuando la historia se transforma en el teatro de la existencia, la organización misma de la sociedad se convierte en marco y fundamento del drama humano. De ahí que las ficciones históricas 
discurran en periodos de transición y crisis, en aquellos puntos donde se juegan los destinos colectivos. (1997, p. 39)

Lois Parkinson propone un concepto arraigado en la naturaleza de la conciencia histórica de la sociedad latinoamericana en particular, proyectado palpablemente en su literatura: la angustia de los orígenes.

Observo, en forma sistemática, que una angustia acerca de los orígenes impulsa a los escritores americanos a buscar precursores (en nombre de la comunidad) más que a escapar de ellos (en nombre de la individualización); a vincularse con las tradiciones y las historias (en nombre de un pasado utilizable) más que a disociarse de ellas (en nombre de la originalidad). (2004, p. 25)

La literatura histórica de América busca, en contraste con la europea señalada por la autora, definir una conciencia colectiva que tenga como base lógica el conocimiento y la interpretación históricos, que fije en la esencia misma de la identidad americana - que deviene a su vez sus identidades individuales - el discurso de su realidad histórica, pasada y presente. Esto se manifiesta siempre alejado de una intención dogmática, moralista o institucional. Parkinson señala que una característica de esta angustia literaria es precisamente la apertura al dialogismo, a la comparación paralela de discursos, no a su mutua negación. Por ello la NNH en especial se permite la enunciación de diversas voces, tiempos y realidades mediante su lenguaje; como lo señala la propia autora, “esta angustia americana genera estructuras literarias incluyentes, relativas, heterogéneas, sincrónicas. [...] Rechazan la hegemonía" (Parkinson, 2004, p. 25).

Parte del concepto que construye Parkinson deviene no (o no únicamente ni de manera primordial) de la necesidad por encontrar una génesis concreta y tangible de la realidad histórica americana, sino que, al carecer de un conocimiento claro y consensual sobre ella, se origina una angustia por los vacios en la propia identidad de lo latinoamericano, lo cual da lugar en su literatura -y no de manera exclusiva en la categóricamente histórica - a construir esa conciencia 
interpretativa del pasado, a establecer un discurso histórico propio que permita el entendimiento de la historia misma, desconocida y ajena sin la intervención del discernimiento literario.

Los autores de los que me ocupo rechazan en forma unánime este mito del Nuevo Mundo de que los americanos no cargan con el peso de la historia porque tienen la libertad de crear la propia. Por el contrario, ponen en escena el hecho de que la historia puede ser más pesada -y más significativa- cuando es uno el que debe crearla. [...] Cuando las tradiciones culturales están separadas o destruidas, y el potencial para la proyección histórica es aparentemente interminable, esa historia se vuelve problemática y la literatura, instrumental. (Parkinson, 2004, pp. 23-24)

Se determina así que la novela histórica en Latinoamérica tiene un carácter discursivo concreto, aunque las características de este discurso le permitan, en aparente contradicción, ser amplio, heterogéneo y dialógico. Se preocupa por la construcción de la historia como elemento de la realidad americana, no únicamente como conocimiento utilitario (aunque no sea posible del todo desdeñar esa posibilidad, como también indica Parkinson), sino como entendimiento y crítica, como derrocamiento de una historia única, hegemónica, que es sustituida por una historia plástica, multifacética y, por lo tanto, relevante para todos los miembros de la sociedad que ella misma ha cimentado. La ficción, como contrapunto de una matriz de sentido, no sólo se compara con la realidad histórica, sino que la asimila para reconstruirla en distintas voces, en distintos mundos posibles que conciban la conciencia de los orígenes de una identidad colectiva.

Queda antes de continuar al análisis aclarar la cuestión de nomenclatura del género. Esta investigación ha tomado como modelo la categoría acuñada por Seymour Menton, Nueva Novela Histórica. Peter Elmore y Lois Parkinson, que ya han sido citados, así como diversos autores que han escrito sobre el tema, deciden hablar únicamente de novela histórica; Elmore en particular habla de la novela histórica contemporánea, quizá por lo restrictivos que resultan los requisitos de admisión a la categoría de Menton, pese a que la producción literaria que no los cubre sigue siendo relevante y numerosa. Conviene emplear el término, sin embargo, por las siguientes razones: aunque las seis 
características fundamentales de la NNH puedan no ser cubiertas a cabalidad por diversas novelas, tampoco las dejan completamente de lado; de hecho, son únicamente la distorsión de hechos históricos y el barroquismo carnavalesco los puntos que se ven excluidos con mayor frecuencia en las narraciones históricas contemporáneas, lo cual no resta importancia a los otros elementos, y mucho menos las despoja de las virtudes que Elmore, Parkinson y el mismo Menton atribuyen al género. Por otra parte, mientras la novela histórica en general puede ser rastreada desde el siglo XIX, y aún antes si se le permite libertad a su categorización, la NNH remite únicamente a obras publicadas a partir de la segunda mitad del siglo XX. Es necesario y pertinente no dejar de mencionar, así pues, que la validez del término de Menton es tema no exento de ejercicios de polemización ${ }^{1}$.

\section{Hacia un horizonte de expectativas del género}

Antes de pretender cualquier intento de análisis formal, es necesario realizar algunas precisiones en cuanto al horizonte de expectativas que se establece como contexto de la NNHH.

Las características que determinan a este género existen precisamente en un horizonte de expectativas como lo define Hans-Robert Jauss, y no sólo en elementos formales y textuales.

La recepción interpretativa de un texto presupone siempre el contexto de experiencia de la percepción estética: la cuestión sobre la subjetividad de la interpretación y el gusto de lectores o sectores de lectores diversos, sólo puede formularse de una manera lógica si se ha aclarado antes cuál es el horizonte transubjetivo del entendimiento que condiciona el efecto del texto. (2000, pp. 164-65)

Los lectores que se acercan a una de estas obras, aun con las intenciones más dispares entre sí, la lectura de entretenimiento o el análisis erudito, lo hacen con la plena conciencia de que el mundo ficticio de la obra involucra de manera primordial la historia, el discurso científico acerca de hechos

\footnotetext{
${ }^{1}$ Consúltese, por ejemplo: Grützmacher, L. (2006) Las trampas del concepto "la nueva novela histórica" y de la retórica de la historia postoficial. Recuperado de https://revistas-filologicas.unam.mx/actapoetica/index.php/ap/article/view/193
} 
concernientes al pasado de una nación, una cultura o un sector social. Es importante remarcar esta situación porque será la primera instancia (primera regla, si se admite) para la interpretación de las obras que se enmarquen en esta categoría. La relación del lector con los textos estará regulada siempre por la aceptación tácita y consciente de que éstas relatan hechos ligados con un discurso ajeno al meramente literario y que, además, determinan el entendimiento presente de su realidad histórica. Se presentará siempre no sólo la posibilidad, sino la expectativa imperante de determinar la lectura en función de una intención ilocutiva concreta; la más eminente será la de desacralizar la historia oficial. Debe tomarse todo ello en cuenta a la luz de un lector implícito con las intenciones antes descritas, dada la "lectura contractual", como la llama María Cristina Pons en Memorias del olvido (1996), que caracteriza a la NNHH.

Un aspecto que deriva de esta circunstancia, y que es necesario considerar y definir para el análisis, es la expectativa de la lectura en cuanto al nivel de ficcionalización de los hechos históricos. Algunos lectores podrían acercarse a estas novelas queriendo encontrar cursos mínimos de historia, lo cual resultaría en una expectativa incongruente con la intención crítica antes planteada y con la naturaleza eminentemente literaria de los textos. Pons por su parte lo describe de la siguiente manera:

La novela histórica de finales del siglo XX emplea estrategias y prácticas narrativas de la novela de su tiempo (de la nueva narrativa). Después de todo, la novela histórica es una novela. En Noticias del Imperio, por ejemplo, se emplea la parodia, lo burlesco y la ironía, la inversión carnavalesca, la desublimación de los discursos, la multiplicidad de voces y puntos de vista. (Pons, 1996, p. 107)

Es claro que considerar absolutamente todas las posibilidades de interpretación es una tarea efectivamente irrealizable, por lo que, tomando la regulación del un lector implícito, el análisis en este caso se realizará a partir de la lectura que este tipo de textos supone; es decir, aquella que les otorga la libertad literaria pertinente a cualquier otra clase de novela y les permite resignificar cualquier elemento temático que empleen en su construcción. Será esa libertad la que permitirá 
contrastar los distintos discursos presentes estructuralmente en las novelas, y fenomenológicamente en el imaginario y expectativas de los lectores. El género ni siquiera demanda un conocimiento histórico pleno para la interpretación más elemental; únicamente requiere de sus lectores convenir en los estatutos de su contrato ficcional.

\section{La literatura como reconfiguración de la historia en Los pasos de López, de Jorge Ibargüengoitia}

Los pasos de López se presenta como un caso claramente pertinente para el análisis por ser una novela que responde directamente a las expectativas que el género plantea antes sus lectores: la desacralización del discurso oficialista de la historia. Aunque el texto logra develar muchos otros planos discursivos, la desmantelación de la historia oficial y sus valores institucionales incólumes es una clara intención que logra verse durante toda la narración. Jorge Ibargüengoitia es identificado como un escritor representativo del humorismo mexicano (muy a su pesar, según algunas de sus declaraciones), lo cual, aunado a reconocer al texto como una novela histórica, ya propone una lectura irreverente de lo que es enunciado con tono solemne en casi en cualquier otro contexto.

La novela toma como tema y escenario espacio temporal de su narración los hechos que condujeron a la Conspiración de Querétaro, encabezada por los corregidores Miguel Domínguez y su esposa Josefa Ortiz, a adelantar su planeado levantamiento revolucionario en contra de la dominación española durante el virreinato en México, con el propósito de independizar a la región de la Nueva España de la Corona, la cual coartaba en casi todos los aspectos sociales y económicos el desarrollo de la población criolla, sin mencionar el de las razas nativas sometidas. La Conspiración, como es sabido, contaba con la participación de varios otros personajes que también buscaban la emancipación para con España, como Ignacio Allende e Ignacio Aldama; pero entre ellos, el más notable, tanto para la historia como para la narración de la novela, es el cura Miguel Hidalgo, a quien se atribuye haber comenzado el primer levantamiento insurgente con el conocido Grito de Dolores, la madrugada del 16 de septiembre de 1810. Esta secuencia de hechos toma parte durante la primera mitad de la novela, señalado su fin por este acontecimiento. La segunda mitad (que no es marcada como tal por ningún capítulo o señalamiento estructural, pero que conviene 
separar por razones que se verán más adelante) recorre las andanzas de la comitiva insurgente - que no era estrictamente un ejército - liderada por Miguel Hidalgo hasta que es desbandada por las fuerzas españolas, sus líderes son dispersados, e Hidalgo es capturado y ejecutado, hecho con el que termina la narración en la novela.

Uno de los recursos con los que cuenta la NNHH para ficcionalizar el discurso histórico, que no necesariamente involucra el barroquismo que demanda Menton, es el conducir los hechos históricos en una trama que se desarrolla alrededor de personajes individuales. Ibargüengoitia convierte la historia del levantamiento independentista en un thriller de conspiraciones y en una comedia de enredos, al menos durante la primera mitad, lo cual no es necesariamente falso o hiperbólico (y cuando lo es, lo es de manera claramente intencionada) con respecto del discurso histórico original, pero da lugar a interpretar hechos concretos desde una perspectiva esencialmente distinta a la no literaria, y radicalmente distanciada de la historia oficial.

Es justo esta intención de convertir la narración histórica en una más emparentada con los géneros de entretenimiento popular una de las herramientas más eficaces para la desmitificación del discurso institucional. Convertir lo no ficticio en ficción, la historia tantas veces alabada en asambleas escolares, rituales gubernamentales y campañas de nacionalismo, en un relato que no se distingue en sus elementos narrativos de otras obras asociadas con un divertimento ajeno y alejado de la realidad inmediata, acerca los temas y los personajes tratados en la novela a un reconocimiento más personal, empático, con sus lectores, lo que, paradójicamente, determina de manera más patente la relación con su entorno.

La comicidad de la primera parte de la novela (que permanece en la segunda, pero con implicaciones algo distintas) da muy clara pauta a la desmitificación también en otro sentido; los hechos históricos y heroicos que se conocen como fundamento del discurso oficial fueron (o pudieron serlo, que es lo importante para esta intención) concebidos como malentendidos, argucias y engaños mañosos, como tantas otras cosas suceden en la vida cotidiana de cualquier individuo. Tómese como ejemplo la siguiente cita: 
[Carmelita] hablaba en un tono que me pareció artificial. El presbítero Concha llegó junto a ella y le habló:

- ¿Y ese papel que tienes en la mano?

Ella lo miró sin comprender.

- ¿Papel? ¿Cuál papel? ¡Ah, este que tengo en la mano! Es una canción que el maestro de canto me dejó aprender para la próxima clase. (Ibargüengoitia, 2013, pp. 38-39)

Nótese la situación burlesca, como de entremés cervantino, que denota en primera instancia una clara intención literaria en la construcción del relato que, sin llegar a ser caricaturesco, establece que de la historia como discurso también se pueden obtener relatos literarios, de la misma manera que relatos con características literarias pueden constituir momentos históricos.

Karim Benmiloud señala también la relación que existe entre la teatralidad de la narración en la novela con la obra de teatro que los personajes ensayan en las tertulias de la Casa del Reloj, que eran las reuniones en que se planeaba la Conspiración. La inclusión de esta obra, La pretensión inútil, que es el verdadero subtítulo del célebre Barbero de Sevilla, comedia de Pierre-Augustin de Beaumarchais, es de donde obtiene su alias Domingo Periñon, la persona ficticia de Miguel Hidalgo en la novela. Esto es un artificio literario mediante el cual Ibargüengoitia simboliza la naturaleza cómica de las historias, la suya y la oficial.

Existe pues un vínculo estrecho entre el artificio del teatro (que es también disimulo, cautela, doblez) y la actuación del joven narrador-artificiero. Al exhibir así la comedia de enredo como modelo implícito de la trama del relato, la novela identifica la acción política como una serie de ardides y trampas urdidos por individuos que sólo buscan engañar a otros para su provecho personal. [...] La obra de teatro interesa cuanto más que entrega aquí, en clave menor, el secreto de la relación que mantienen los 'héroes' con la escenificación, la ilusión, la duplicidad, la doblez y el artificio.

Es más, a la misma Historia se la denuncia, no sólo como relato, construcción o artefacto, sino también como impostura y mistificación. (Benmiloud, 2010, p. 10) 
Es posible entonces interpretar el evidente uso de los géneros literarios como comentario retórico para con la realidad histórica. El hecho de que sea el teatro el género que se aborda implica algunas significaciones pertinentes. En México y otros países hispanohablantes es común la expresión "hacer, echar o armar un teatro" cuando una situación cotidiana es exagerada por sus participantes para darle un tono melodramático. Ibargüengoitia, desde esta perspectiva, está verdaderamente armando un teatro a partir de los hechos históricos y de sus actantes.

Por si el hecho de involucrar una obra dramática dentro de la diégesis no fuera ya símbolo suficiente, el autor emplea una estructura de diálogos teatrales para narrar uno de los episodios más importantes de la trama, el descubrimiento de la Conspiración. El capítulo quince, justo el último de la primera parte, termina no con la narración convencional de Matías Chandón, el personaje narrador, sino como un diálogo dramático escrito como tal, incluyendo las acotaciones para los actores; no se logra esto mediante ningún cambio de voz narrativa ni de la estructura del texto, como sucede en diversas obras contemporáneas (2666 de Roberto Bolaño, por ejemplo), sino mediante una retórica bastante más simple y consistente: el narrador explica los hechos que condujeron a Adarviles, probable personificación al capitán Joaquín Arias, a traicionar la Conspiración ante las autoridades virreinales. Adarviles, el alcalde y el licenciado Manubrio fraguan un engaño ante los corregidores, a quienes, por la denuncia de Adarviles, ya han reconocido como culpables, pero fingirán desconocerlo, así como el involucramiento del capitán, para evitarle a este alguna represalia. Por su parte, Diego y Carmen fingirán estar fielmente del lado de la Corona hasta el momento en que son irremediablemente expuestos por el documento probatorio de Adarviles, la carta mediante la cual Carmen le ha instado a comenzar la insurrección armada. Cada "compañía" ensaya e interpreta su guion al momento de su encuentro, y no deponen sus papeles sino hasta que “cae lento el telón":

Manubrio: ¿Y estas botas de quién son?

Carmen y Diego: ¿Cuáles botas? (Ochoa y Manubrio sacan pistolas que traen bajo las capas. Pretendiendo protegerlos, arrinconan a los Aquino, cortándoles el camino a la puerta y a las ventanas.) 
Manubrio (apuntando): El que está detrás de la cortina que salga de allí.

(Aparece Adarviles con las manos en alto. Ochoa va a la ventana y la abre.)

Ochoa (hacia afuera): Alguaciles, a mí.

Diego pretende no comprender cómo pudo el capitán Adarviles llegar a estar escondido detrás de la cortina de su sala. Carmen está desesperada. Entran dos alguaciles.

Ochoa (a Adarviles): Capitán, su espada.

Adarviles entrega su espada.

Ochoa (a los alguaciles): Regístrenlo, por si tiene otras armas.

Los alguaciles registran a Adarviles y encuentran entre sus ropas un papel doblado que ponen sobre la mesa.

Manubrio (con interés): ¡Un papel doblado! (Lo abre lleno de curiosidad y lee.)

Ochoa: ¿Qué dice?

Manubrio (pretendiendo apenas poder dar crédito a sus ojos): Es una carta de doña Carmen, pidiéndole al capitán Adarviles que se levante en armas esta noche 'y ejecute las operaciones que la Junta había dispuesto para el cuatro de octubre'.

Ochoa y Manubrio miran a los Aquino llenos de reproche.

Ochoa (a Diego): ¿Tiene usted algo que decir en defensa de la señora, don Diego?

Diego (con la mirada baja): Ella no tiene nada que ver. Yo soy culpable de todo.

Ochoa (a Diego): Don Diego Aquino: a nombre del Cabildo de esta ciudad, lo depongo de sus funciones y lo hago prisionero.

Cae lento el telón. (Ibargüengoitia, 2013, pp. 115-16)

Como muestra esta cita, la teatralidad, la literariedad de estos hechos ya es bastante evidente desde que comienza la narración original de Matías Chandón, tanto por su naturaleza cómica como por existir dentro de un relato narrativo. Lo que logra esta escenificación es consolidar la edificación del discurso ficticio, lo manifiesta abiertamente como la lente crítica que pretende ofrecerse a los lectores para leer la historia de manera distinta. Tiene ahora el texto tanta confianza en que los lectores ya se han apropiado de esta mirada irónica que justo el siguiente capítulo comienza diciendo que "El episodio que sigue es tan conocido que no vale la pena contarlo" (Ibargüengoitia, 
2013, p. 117), refiriéndose a uno de los sucesos más importantes y conocidos de la historia de la independencia mexicana, el Grito de Dolores. Aún sin la punzante precisión del capítulo anterior, el autor tiene razón en no demostrar demasiado esfuerzo en representar esta escena debido a su prominencia dentro del discurso histórico popular. Dentro del contexto mexicano en particular, es el hecho más conmemorativo de toda la narración independentista, pues es en el que se sustenta la celebración tradicional de las Fiestas Patrias. Es claro, pues, que tal hecho no necesita ni la elaboración narrativa ni la trascendencia que ello podría otorgarle, por lo que la novela se vale de la perspectiva planteada anteriormente para implicar que los eventos del Grito también pueden ser interpretados a través de la desmitificación, la cual, no obstante, tiene un matiz particular dentro del relato; en lugar de "armar un teatro", como con la escena de los Corregidores, los sucesos del aquí llamado Grito de Ajetreo son más bien minimizados, tanto por la brevedad de su exposición como por la relevancia que se les asigna; es decir, casi ninguna. La liberación de presos hecha por Domingo Periñón, que enmarca su alzamiento como libertador del pueblo oprimido por la Corona, es inmediatamente nulificada por la posterior fatalidad confirmada en la narración de Chandón:

Entonces oí a Periñón decir su primer discurso revolucionario:

- Libertad os doy - dijo a los presos - porque habéis sido víctimas de un gobierno injusto.

-iViva el señor cura Periñón! - gritaron los presos.

Lo siguieron lealmente en su aventura. Todos murieron. (Ibargüengoitia, 2013, p. 118)

El Grito mismo, en esta escenificación literaria, no representa un inicio heroico, sino apenas una sublevación artificial, no por falsa, sino por no tener más consecuencias que hacer notorio que la revuelta había comenzado, pero sin ningún logro significativo: “Ni él [Periñón) gritó 'ivamos a matar españoles!', ni matamos a ninguno aquella noche. Periñón abrió una barrica del vino que él mismo hacía y nos dio a probar. Estaba agrio. Después dispuso guardias y nos fuimos a dormir" (Ibargüengoitia, 2013, p. 119).

Este constante menoscavar los hechos -incluyendo la mención de que el vino estaba agrio- deja muy claro para los lectores el tono que se atribuye a este momento tan importante en 
la historia oficial. Ni siquiera se hace una yuxtaposición entre la ficción del texto y la realidad, sino que el propio texto explica que lo que está haciendo es "precisar algunos puntos que la leyenda ha borroneado" (Ibargüengoitia, 2013, p. 117), un giro por demás contrastante con el teatro del capítulo anterior, pero no menos determinado a asentar su intención crítica.

Otra herramienta del texto para la desacralización de la historia es quizá la más evidente, pero que da pie a múltiples lecturas: el cambio de los nombres propios. El mismo título de la novela ya desconcertará a los lectores que en su horizonte de expectativas prevén una narración de hechos y personajes históricos, más aún cuando el primer personaje mencionado en el texto tiene un nombre propio distinto al del título y al de cualquier prócer nacional. Periñón es el apellido del personaje en torno al cual gira la mayor parte de la narración; no toda, ciertamente, pues él no es el protagonista de muchos pasajes, ni el narrador del texto; éste último, Matías Chandón, permite entrever claramente que la persona que encarna Domingo Periñón en la novela es el cura Miguel Hidalgo y Costilla, a quien cualquiera familiarizado con el discurso histórico oficial mexicano podrá reconocer como el Padre de la Patria. Esta relación da cuenta por sí misma de las intenciones ilocutivas del autor al convertir al hecho mismo en una nimiedad y a su personaje principal en una figura más bien excéntrica y muy poco solemne, lo cual es visible no sólo en este pasaje, sino a lo largo de la novela.

Cuando yo le preguntaba cómo le había hecho para regresar a América, nomás movía la cabeza, como quien quiere borrar un recuerdo amargo.

-Bástete saber que llegué a Veracruz con la sotana muy revolcada - agregaba.

[...] La sombra del viaje oscureció su carrera eclesiástica, que había comenzado tan bien. Cuando alguna oportunidad se le presentaba - un puesto de secretario en la Mitra, una cátedra, una parroquia importante- no faltaba quien se la echara a perder recordando que era jugador, que empezaba una cosa y terminaba haciendo otra, que no pagaba deudas, etc. (Ibargüengoitia, 2013, pp. 7-8)

Por otra parte, el cambio de nombres propios, tanto de personas como de lugares, abre un juego interpretativo por demás complejo pero eficiente en entablar una cooperación entre texto y lector. 
La primera tarea con la que se ve enfrentado el lector es reconocer lo mejor que pueda, mediante su conocimiento histórico, a los personajes y hechos narrados, qué personaje real representa cada personaje literario y a qué lugar se refieren los mencionados por nombres ficticios. Algunos son sumamente sencillos (asumiendo el conocimiento mínimo que el texto supone en su lector implícito), como los corregidores Diego y Carmen Aquino, claramente personificando a Miguel y Josefa Domínguez, el propio Domingo Periñón, y el capitán Aldaco, representación de Juan Aldama. Este juego de memoria y reconocimiento no únicamente mantiene a los lectores que quieran participar en él (lo cual en ningún momento es obligatorio para disfrutar la narración o para entender sus intenciones discursivas) con una atención alerta a otros mensajes implícitos, sino que permite que la yuxtaposición de la ficción y la realidad sea el código de interpretación más prominente; la crítica al discurso institucional no es mermada por que los nombres sean distintos a los originales, sino todo lo contrario, es acentuada por ello.

Otro aspecto de este artificio es el que confirma la naturaleza dramática de la historia misma como discurso acerca de la realidad. Que los personajes de la narración aparezcan como nuevas figuras refuerza la idea de la teatralidad con la que Ibargüengoitia ha confeccionado el texto. Es posible interpretar que los personajes del teatro histórico son los mismos héroes nacionales actuando un papel cómico, presentando sus créditos como en una marquesina: Miguel Hidalgo y Costilla como el cura Domingo Periñón, con la participación de Josefa Ortiz como Carmelita Aquino. La idea de que las personalidades están actuando como ellas mismas, y que su actuación en esta obra sea de carácter cómico y burlesco, construye una dimensión más del sentido de crítica de la historia, de la historia como relato y de la literatura como replanteamiento del discurso histórico.

La figura particular de Matías Chandón como elemento de la narración es importante por diversos factores, comenzando por lo más superficial (por estar en la superficie, no porque ello pudiera resultar banal), su papel como narrador, el cual, pese a todas la peripecias retóricas con las que el autor logra las intenciones discursivas hasta ahora expuestas, es realmente simple, alejado de cualquier complicación narratológica que textos como El arpa y la sombra, Los perros del Paraíso y otras Nuevas Novelas Históricas con características neobarrocas emplean abiertamente. Chandón, 
gracias a su narración presencial en primera persona, es el conducto directo mediante el cual los lectores se adentran en el mundo ficcional de la narración, característica inherente de cualquier narrador de esta naturaleza. Pero este personaje involucra otro factor trascendental: Matías Chandón es un personaje enteramente ficticio, es decir, no representa a ningún héroe de la historia oficial, su persona y su papel en la trama son invención del autor. Esto da pie a múltiples circunstancias interpretativas. Primero, reconocerlo como un agente intruso dentro de los hechos históricos destierra de entrada cualquier confusión entre los hechos históricos mismos y el mundo de la novela; el lector será capaz de asumir que el texto no es simplemente una versión novelada del discurso histórico, sino un discurso por completo literario que involucra, por razones que le han parecido necesarias al autor, elementos de la historia. La consciencia de esta relación es lo que posibilita la efectiva comunicación de las intenciones que ya se han señalado.

Por otra parte, la personalidad y situación de Matías Chandón condiciona la perspectiva desde la que el relato es narrado. Matías es un personaje capaz, aunque necesariamente auxiliado por la intervención de otros personajes, de las tareas que sus circunstancias le demandan: sigilo en la convivencia con las autoridades virreinales, coordinación y liderazgo en la campaña militar, y sutileza social en el trato con sus compañeros conspiradores, en especial con Carmen Aquino. Pero a pesar de todo ello, no puede evitar ser arrastrado por las consecuencias del devenir de los hechos históricos, lo cual es notable dada su existencia ficcional. Incluso en su posición influyente en distintos círculos, como jefe de artificieros dentro del ejército que responde a la Corona y como estratega y cómplice de los criollos insurgentes, la realidad histórica es lo que determina en última instancia su desenvolvimiento en la trama, casi siempre para su infortunio y para el de sus aspiraciones. Tómese como ejemplo de lo anterior el siguiente pasaje:

Le he contado este caso, don Matías - terminó diciendo el licenciado-, para que sepa qué terreno pisa. Usted viene de Perote en donde la vida será aburrida, pero se respira un aire mejor, las tropas de allí son leales a la Corona. Ahora va usted a un nido de víboras. Esta región está llena de criollos resentidos: gente incompetente que se siente postergada. He querido abrirle los ojos. 
Y me los abrió, porque hasta ese momento yo había creído que las revoluciones eran sucesos que ocurrían en el extranjero. (Ibargüengoitia, 2013, p. 13)

Se construye aquí una realidad histórica a partir de dos puntos de vista distintos: uno partidario del lado del régimen español sobre la colonia, y otro relativamente neutro, pero que pasará luego a ser parte de la revolución, para que el lector compare su propia percepción de la realidad histórica colonial inmediatamente anterior al levantamiento independentista. Chandón cumple su cometido como conducto para el lector hacia el mundo de la obra, y al mismo tiempo dirige la mirada hacia los puntos de atención necesarios para las intenciones discursivas del texto; textualmente, abre los ojos del lector.

La segunda parte de la novela no cambia el tono de las intenciones discursivas puestas en acción por la primera ni de la construcción dramática de los hechos históricos, sino que continúa implementándolos en la circunstancia que ahora tiene lugar, la avanzada del Primer Ejército Libertador. Este nuevo escenario cambia la dinámica narrativa por la naturaleza de los hechos mismos, pues ya no se tratará de una comedia de enredos y traiciones, sino de la cuenta cuasiépica de esta andanza militar. Por lo tanto, la manera en que tales acontecimientos son vistos mediante la lente crítica del texto propone un acercamiento más parecido al presentado en el capítulo dieciséis, el del Grito de Ajetreo, es decir, la desacralización mediante una representación pesimista y demeritoria. Es en esta parte que el personaje de Domingo Periñón cobra su mayor relevancia, pues es él quien asume el mando absoluto del ejército, mientras Aldaco y Chandón fungen como tenientes.

El juicio más contundente planteado sobre esta realidad histórica es que el ejército insurgente estaba compuesto por jornaleros, obreros y hasta reos liberados indiscriminadamente, por lo que era un grupo sumamente desorganizado e indisciplinado, lo que significó en gran medida su fracaso como frente armado y las consecuencias que ello tuvo para sus líderes. El discurso oficial no expone lo contrario, pero le otorga a ello un hálito de nobleza de espíritu, por el que aun la población humilde e impreparada puede alcanzar heroísmo al luchar por sus ideales; la 
contrarréplica de Los pasos de López es que tal situación simplemente echó abajo los logros y el esfuerzo de los insurgentes, y de los propios ideales del pueblo.

Desde entonces hasta la fecha muchos nos han acusado a los jefes insurgentes de sanguinarios. ¿Que por qué no evitamos la matanza de Requinta? Porque no pudimos. Tratamos de detener a la gente pero no nos obedecieron. No era un ejército, era un gentío. (Ibargüengoitia, 2013, p.133)

Es importante hacer ver que la intención crítica de la novela no se atiene exclusivamente a los hechos comprendidos por esta narración. Aunque los hechos aquí representados son evidentemente trascendentales para el discurso de la historia mexicana, es necesario cuestionar todos los hechos del pasado que conforman la identidad nacional y la manera en que se entiende la situación presente de la realidad. El final del capítulo veintiuno menciona tangencialmente el encuentro entre Periñón y José Atanasio Redondo, posible alias novelesco de José María Morelos, caudillo que continuó con la lucha de independencia después de que se disolviera el primer ejército y Miguel Hidalgo fuera fusilado en Chihuahua. Tal mención liga esta narración, junto con su particular representación del discurso histórico que ficcionaliza, con el discurso histórico general, volviendo posible expandir la mirada crítica que esta novela plantea más allá del tiempo y el espacio a los que refiere explícitamente.

Finalmente, la novela concentra toda su ambición desmitificadora en Domingo Periñón. Tras el absoluto fracaso del Ejército Libertador, Periñón se dirigió voluntariamente a la obvia emboscada que Adarviles preparó disfrazada de conspiración contra los españoles, para luego ser aprehendido y encarcelado. Mientras los otros jefes insurgentes fueron inmediatamente enjuiciados y ejecutados, el proceso de Periñón se dilató por seis meses en los que las autoridades españolas buscaban convencerlo de firmar una contrición en la que se arrepintiera de sus acciones contra el virreinato. Al final pide que traigan el documento y lo firma, pero no con su nombre, sino con su alias dramático: López. Esta conclusión es lo bastante ambigua para permitir distintas lecturas, pero a la luz del análisis hasta ahora realizado, la firma con el nombre doblemente ficticio confirma la 
perspectiva posible únicamente desde la ficción literaria. Miguel Hidalgo personifica en el discurso histórico oficial los valores de la gesta heroica, de la insurrección contra la Corona española y de los ideales del pueblo: Hidalgo personifica a la historia oficial misma. Que Periñón se muestre hasta el último momento como un actor burlesco, y lo confirme con la firma de López, concluye tajantemente que lo que se reconoce como la historia oficial de México es un teatro, un mito artificialmente construido.

La novela no es la cuenta de "la verdead histórica", no son hechos ocultos finalmente revelados; es una perspectiva como puede serlo cualquier otra, pero en ello estriba su intención, como la de la Nueva Novela Histórica como género: si lo que se conoce oficialmente es ficción en sí mismo, existe la libertad de crear distintas ficciones para acercarse a la realidad histórica, y para interpretar el presente a la luz de las múltiples explicaciones posibles.

\section{Referencias}

Benmiloud, K. (2010). Los pasos de López de Jorge Ibargüengoitia: La independencia mexicana dinamitada [Versión electrónica]. Montpellier: Université Montpellier.

Elmore, P. (1997). La fábrica de la memoria. México: Fondo de Cultura Económica. Ibargüengoitia, J. (2013). Los pasos de López. México: Booket.

Jauss, H. (2000) La historia de la literatura como provocación. Barcelona: Península.

Menton, S. (1993). La nueva novela histórica de la América Latina, 1979-1992. México: Fondo de Cultura Económica.

Parkinson, L. (2004) La construcción del pasado. México: Fondo de Cultura Económica.

Pons, M. C. (1996) Memorias del olvido: la novela histórica de fines del siglo XX. México: Siglo XXI Editores. 